\title{
Гордеева Н.И.
}

Центральный сибирский ботанический сад Северного отделения РАН, г. Новосибирск

\section{ОНТОГЕНЕТИЧЕСКАЯ И ПОЛОВАЯ СТРУКТУРЫ ЦЕНОПОПУЛЯЦИЙ ORIGANUM VULGARE L. (LAMIACEAE)}

Аннотация. Origanum vulgare L. (Lamiaceae) является ценным лекарственным и кормовым растением. Исследованы онтогенетическая и половая структуры пяти ценопопуляций вида в Республике Алтай и Алтайском крае. Растения 0. vulgare в луговых разнотравнозлаковых фитоценозах фрормируют длиннокорневищную жизненную фрорму. В онтогенетической структуре ценопопуляций преобладают средневозрастные генеративные особи. Семенное возобновление растений незначительно; самоподдержание ценопопуляций происходит в основном вегетативным путем. В половой структуре ценопопуляций доля женских особей составляет от 18\% до $31 \%$.

Ключевые слова: Origanum vulgare, ценопопуляция, онтогенетическая структура, половая структура.

\section{N. Gordeeva (Novosibirsk, Russia) \\ ONTOGENETIC AND SEXUAL STRUCTURE OF ORIGANUM VULGARE L. (LAMIACEAE)}

Central Siberian Botanical Garden, Siberian Branch of the Russian Academy of Sciences

Abstract. Origanum vulgare L. (Lamiaceae) is a valuable medicinal and forage plant. The ontogenetic and sexual structure of five meadow coenopopulations has been studied in the Altai Republic and Altai Krai. Plants of Origanum vulgare in the phytocenoses form a long-rhizomatous life form. In the ontogenetic structure, generative individuals dominate. Seed regeneration of plants is insignificant; the coenopopulation stability is ensured due to the vegetative reproduction. The proportion of female individuals in populations is found to be $18 \%-31 \%$.

Key words: Origanum vulgare, coenopopulation, ontogenetic structure, sexual structure.

Душица обыкновенная - Origanum vulgare L. (Lamiaceae) - голарктический лесостепной вид; травянистый многолетник; встречается по суходольным и остепненным лугам, в разреженных лесах, в кустарниках, на каменистых склонах [8]. Вид является ценным лекарственным и кормовым растением [7, с. 343]. В зависимости от условий произрастания растения могут иметь короткокорневищную или длиннокорневищную жизненные формы. Онтоморфогенез O. vulgare изучался в природных местообитаниях [9; 11] и в условиях интродукции [9]. В литературе практически отсутствуют материалы по исследованию онтогенетической структуры природных

(С Гордеева Н.И., 2015. 
популяций. По половому типу вид относится к гинодиэцичным растениям, в популяции которых произрастают совместно обоеполые особи с гермафродитными цветками и женские особи с пестичными цветками [5, с. 223-224; 6]. Исследования половой структуры $O$. vulgare малочисленны $[1 ; 2]$. Изучение особенностей онтогенетической структуры, полового полиморфизма и половой структуры ценопопуляций из разных местообитаний необходимо для выяснения механизмов поддержания гинодиэции в природе и адаптации вида к условиям биотопа [3; 14]. Цель работы - исследование онтогенетической и половой структуры Origanum vulgare в природных популяциях в Республике Алтай и Алтайском крае.

Материалы и методы. Исследования проводили в 5 луговых ценопопуляциях (ЦП) Республики Алтай и Алтайского края.

ЦП-1. Разнотравно-злаковый луг на каменистом склоне (Dactylis glomerata L., Elymus gmelinii Tzvelev., Phleum pratense L., Geranium pratense L., Vicia cracca L.), общее проективное покрытие (ОПП) травостоя - 100\%, проективное покрытие (ПП) O. vulgare - 3\% (Шебалинский p-н, окр. пос. Улус-Черга).

ЦП-2. Разнотравно-злаковый луг на каменистом склоне (Elymus gmelinii Tzvelev., Dactylis glomerata L., Brachypodium sylvaticum P. Beauv., Filipendula vulgaris Moench., Galium verum L., Origanum vulgare L., Vicia cracca L.), ОПП травостоя - 100\%, ПП О. vulgare - 5\% (Шебалинский р-н, окр. пос. Камлак).

ЦП-3. Разнотравно-злаковый луг с умеренным выпасом (Alopecurus pratensis L., Dactylis glomerata L., Festuca pratensis Huds., Artemisia vulgaris L., Geranium pratense L., Rhinanthus aesti- valis Schischk.), ОПП травостоя - 100\%, ПП - O. vulgare - 3\% (Алтайский край, окр. пос. Сентелек).

ЦП-4. Разнотравно-злаковый луг (Festuca pratensis Huds., Phleum pratense L., Dactylis glomerata L., Bromopsis inermis Holub., Origanum vulgare L., Filipendula ulmaria Maxim., Fragaria viridis Duch.), ОПП травостоя - 100\%, ПП О. vulgare - 5\% (Алтайский край, окр. с. Алтайское).

ЦП-5. Разнотравно-злаковый луг (Phleum pratense L., Dactylis glomerata L., Origanum vulgare L., Rhinanthus aestivalis Schischk., Filipendula vulgaris Moench., Medicago falcate L., Artemisia gmelinii. Weber ex St., Fragaria viridis Duch.), ОПП травостоя - 100\%, ПП О. vulgare - 8\% (окр. с. Усть-Кокса Республики Алтай).

Онтогенетическая структура ценопопуляций изучалась по общепринятым методикам: трансекты длиной по 1020 м делились на площадки по 1 м² [10; 13]. Учитывались следующие признаки: мощность развития растения, наличие силлептических побегов, число растущих корневищ, степень развития корневой системы побегов, степень развития соцветия. За счетную единицу принималась особь семенного происхождения (ювенильное и имматурное состояние), парциальный куст или парциальный побег вегетативного происхождения (виргинильное, генеративные и постгенеративные состояния). При исследовании полового полиморфизма O. vulgare было установлено, что каждая особь состоит из побегов только одной половой формы. Половая структура популяций изучалась методом трансект общей площадью от 20 до $50 \mathrm{~m}^{2}$, общее число учитываемых особей двух половых форм составляло не менее 100. 
Морфологические измерения проводили на 15-30 особях средневозрастного генеративного состояния для каждой половой формы в каждой популяции. Учитывались следующие показатели: число генеративных побегов особи, число растущих корневищ и годичный прирост плагиотропных корневищ; определялся условный возраст особи. На генеративных побегах отмечались длина побега, длина соцветия и число паракладиев соцветия. Все показатели обработаны статистически [9].

Результаты и обсуждение. Исследование ценопопуляций O. vulgare показало, что растения в луговых разнотравно-злаковых фитоценозах Республики Алтай и Алтайского края формируют длиннокорневищную жизненную форму. При изучении онтогенетической структуры обнаружено, что во всех ценопопуляциях только ювенильные и имматурные растения имеют семенное происхождение. Особи виргинильного, генеративного, субсенильного и сенильного онтогенетических состояний были вегетативного происхождения. Вегетативное разрастание начинается у виргинильных особей путем образования растущих корневищ и достигает максимума у средневозрастных генеративных растений. Виргинильные, генеративные и субсенильные особи представлены парциальными побегами или парциальными кустами, связанными между со- бой гипогеогенными плагиотропными корневищами. В подземной части этих растений формируются одно или несколько растущих корневищ. Вегетативное разрастание генеративных особей часто приводит к образованию омоложенных до виргинильного состояния особей. Сенильные особи однопобеговые и обычно не образуют растущих корневищ.

Анализ биолого-морфологических признаков показал, что, независимо от местообитаний, средневозрастные генеративные особи чаще всего состоят из 1-2 генеративных побегов, максимально - из 4-5 побегов (табл. 1). Число растущих корневищ в парциальном кусте значительно изменяется в разных местообитаниях: меньше всего в ЦП-3 (от 1 до 6) и больше всего в ЦП-4 (от 3 до 12). Уменьшение образования растущих корневищ, возможно, связано с повышенной пастбищной нагрузкой в фитоценозе. Годичные приросты плагиотропных корневищ особей в разных ценопопуляциях заметно не различаются и достигают от 1,5-2,0 см до 9,0-13,0 см длины. Условный возраст особей из разных местообитаний мало различается и составляет 3-5 лет. Установлено, что особи O. vulgare способны произрастать и удерживать за собой территорию до 5-7 лет. Во всех ценопопуляциях плагиотропные участки корневища растений могут достигать длины до 20-23 см.

Таблица 1

Биолого-морфологические признаки средневозрастных генеративных особей обоеполой и женской форм Origanum vulgare

\begin{tabular}{|c|c|c|c|c|c|c|}
\hline \multicolumn{2}{|c|}{ Признаки } & ЦП 1 & ЦП 2 & ЦП 3 & ЦП 4 & ЦП 5 \\
\hline & $\mathrm{O}$ & $\frac{1.5 \pm 0.17^{2}}{47}$ & $\frac{1.8 \pm 0.17}{50}$ & $\frac{1.5 \pm 0.17}{59}$ & $\underline{1.4 \pm 0.22}$ & $\underline{1.2 \pm 0.09}$ \\
$\begin{array}{c}\text { Число генеративных } \\
\text { побегов, шт. }\end{array}$ & Ж & $\frac{1.5 \pm 0.22}{37}$ & $\frac{1.9 \pm 0.40}{58}$ & $\frac{1.6 \pm 0.20}{55}$ & $\underline{1.4 \pm 0.16}$ & $\underline{1.3 \pm 0.16}$ \\
& & & & & 44 & 46 \\
\hline
\end{tabular}


Продолжение таблицы 1

\begin{tabular}{|c|c|c|c|c|c|c|}
\hline \multicolumn{2}{|l|}{ Признаки } & ЦП 1 & ЦП 2 & ЦП 3 & ЦП 4 & ЦП 5 \\
\hline $\begin{array}{l}\text { Число растущих } \\
\text { корневищ, шт. }\end{array}$ & $\begin{array}{l}\text { O } \\
\text { Ж }\end{array}$ & $\begin{array}{l}\frac{5.8 \pm 0.69}{51} \\
\frac{6.3 \pm 0.84}{33} \\
\end{array}$ & $\begin{array}{l}\frac{4.2 \pm 0.68}{85} \\
\frac{4.9 \pm 0.91}{67}\end{array}$ & $\begin{array}{c}\frac{2.8 \pm 0.25}{48} \\
\frac{3.1 \pm 0.50}{69} \\
\end{array}$ & $\begin{array}{l}\frac{6.3 \pm 0.48}{33} \\
\frac{7.2 \pm 1.01}{56} \\
\end{array}$ & $\begin{array}{c}\frac{3.8 \pm 0.31}{50} \\
\frac{4.2 \pm 0.34}{31}\end{array}$ \\
\hline $\begin{array}{c}\text { Годичный прирост } \\
\text { плагиотропных } \\
\text { корневищ, см }\end{array}$ & Ж & $\begin{array}{l}\frac{3.5 \pm 0.26}{55} \\
\frac{3.9 \pm 0.75}{67} \\
\end{array}$ & $\begin{array}{c}\frac{3.8 \pm 0.26}{63} \\
\frac{3.4 \pm 0.44}{71} \\
\end{array}$ & $\begin{array}{c}\frac{3.9 \pm 0.26}{60} \\
\frac{3.5 \pm 0.34}{63}\end{array}$ & $\begin{array}{c}\frac{4.5 \pm 0.33}{57} \\
\frac{4.9 \pm 0.60}{68} \\
\end{array}$ & $\begin{array}{c}\frac{4.8 \pm 0.29}{50} \\
\frac{4.6 \pm 0.49}{59} \\
\end{array}$ \\
\hline $\begin{array}{c}\text { Условный возраст } \\
\text { особи, годы }\end{array}$ & Ж & $\begin{array}{l}\frac{3.7 \pm 0.14}{16} \\
\frac{3.5 \pm 0.22}{16}\end{array}$ & $\begin{array}{l}\frac{3.5 \pm 0.15}{22} \\
\frac{3.4 \pm 0.20}{15}\end{array}$ & $\begin{array}{c}\frac{4.0 \pm 0.20}{27} \\
\frac{4.0 \pm 0.24}{26} \\
\end{array}$ & $\begin{array}{l}\frac{4.5 \pm 0.26}{24} \\
\frac{4.2 \pm 0.22}{23}\end{array}$ & $\begin{array}{c}\frac{3.8 \pm 0.19}{27} \\
\frac{3.5 \pm 0.13}{15} \\
\end{array}$ \\
\hline $\begin{array}{c}\text { Длина } \\
\text { генеративного } \\
\text { побега, см }\end{array}$ & Ж & $\begin{array}{l}\frac{50.0 \pm 1.54}{14} \\
\frac{51.2 \pm 2.23}{12}\end{array}$ & $\begin{array}{l}\frac{64.5 \pm 1.48}{13} \\
\frac{63.8 \pm 2.83}{13}\end{array}$ & $\begin{array}{l}\frac{57.9 \pm 0.91}{9} \\
\frac{56.4 \pm 1.68}{12}\end{array}$ & $\begin{array}{l}\frac{61.6 \pm 1.42}{10} \\
\frac{61.3 \pm 1.45}{11}\end{array}$ & $\begin{array}{l}\frac{49.1 \pm 1.20}{13} \\
\frac{50.4 \pm 1.4}{12}\end{array}$ \\
\hline Длина соцветия, см & Ж & $\begin{array}{l}\frac{8.6 \pm 1.12}{59} \\
\frac{8.3 \pm 1.56}{53}\end{array}$ & $\begin{array}{l}\frac{12.4 \pm 0.75}{33} \\
\frac{10.8 \pm 0.98}{44}\end{array}$ & $\begin{array}{l}\frac{15.1 \pm 1.07}{38} \\
\frac{15.4 \pm 1.10}{26}\end{array}$ & $\begin{array}{l}\frac{16.8 \pm 0.97}{26} \\
\frac{17.4 \pm 0.89}{24}\end{array}$ & $\begin{array}{l}\frac{8.8 \pm 0.74}{45} \\
\frac{9.3 \pm 0.89}{41}\end{array}$ \\
\hline $\begin{array}{c}\text { Число паракладиев } \\
\text { соцветия, шт. }\end{array}$ & Ж & $\begin{array}{l}\frac{3.7 \pm 0.23}{29} \\
\frac{3.6 \pm 0.60}{47}\end{array}$ & $\begin{array}{l}\frac{4.4 \pm 0.17}{21} \\
\frac{4.0 \pm 0.35}{27}\end{array}$ & $\begin{array}{l}\frac{5.2 \pm 0.17}{17} \\
\frac{5.1 \pm 0.18}{13}\end{array}$ & $\begin{array}{l}\frac{5.2 \pm 0.26}{22} \\
\frac{5.5 \pm 0.21}{18}\end{array}$ & $\begin{array}{l}\frac{3.9 \pm 0.23}{31} \\
\frac{4.0 \pm 0.26}{27}\end{array}$ \\
\hline
\end{tabular}

Прим.: ЦП - ценопопуляция, О - обоеполая половая форма, Ж - женская половая форма (показатели рассчитаны на 1 парциальный куст; над чертой - среднее значение и ошибка среднего; под чертой коэффициент вариации, \%).

Изучение онтогенетической структуры O. vulgare показало, что онтогенетические спектры ценопопуляций центрированные со значительным преобладанием средневозрастных генеративных особей, которые составляют $40,2 \%$ - 66,4 \% (табл. 2). Две популяции (ЦП-3 и ЦП-4) имеют неполночленный тип спектра: в них отсутствуют группы ювенильных и имматурных растений (ЦП-3) или только ювенильные растения (ЦП-4). Самый высокий процент ювенильных и имматурных особей отмечен в ЦП-2 - 9,6\%. Исследование ценопопуляций показало, что проростки не обнаружены в ЦП-1, ЦП-3 и ЦП-4, а в ЦП-2 и ЦП-5 они отмечаются еди- нично в нарушенных местах фитоценоза (на муравейниках и др.). Накопление большого слоя ветоши в почве луговых сообществ препятствует прорастанию семян и развитию проростков и ювенильных растений O. vulgare. Увеличение доли прегенеративных растений в луговых фитоценозах, вероятно, связано с локальными нарушениями местообитаний. Участие виргинильных особей составляет в разных фитоценозах от $6,3 \%$ до 24,0\%; субсенильных особей - от 7,1\% до 17,2\%. Самый низкий процент виргинильных и субсенильных растений наблюдается в ЦП-3, что, вероятно, связано с повышенной пастбищной нагрузкой в фитоценозе. 
Процент особей молодого и старого генеративного состояния в популяциях невелик и составляет от $1,9 \%$ до $13,5 \%$. Во всех ценопопуляциях отмечается низкий процент сенильных растений $(2,7 \%-4,8 \%)$.
Таким образом, самоподдержание ценопопуляций $O$. vulgare в исследованных луговых фитоценозах происходит в основном вегетативным путем, вклад семенного возобновления незначителен.

Таблица 2

\section{Распределение особей по онтогенетическим группам в ценопопуляциях} Origanum vulgare

\begin{tabular}{|c|c|c|c|c|c|c|c|c|}
\hline \multirow{2}{*}{ № ЦП } & \multicolumn{7}{|c|}{ Онтогенетические состояния (\%) } \\
\cline { 2 - 10 } & $\mathrm{j}$ & $\mathrm{im}$ & $\mathrm{v}$ & $\mathrm{g} 1$ & $\mathrm{~g} 2$ & $\mathrm{~g} 3$ & $\mathrm{ss}$ & $\mathrm{s}$ \\
\hline ЦП-1 & 2,7 & 1,3 & 24,0 & 5,3 & 50,7 & 2,7 & 10,7 & 2,7 \\
\hline ЦП-2 & 7,7 & 1,9 & 10,6 & 1,9 & 56,7 & 6,7 & 9,6 & 4,8 \\
\hline ЦП-3 & 0 & 0 & 6,3 & 7,9 & 61,9 & 13,5 & 7,1 & 3,2 \\
\hline ЦП-4 & 0 & 0,9 & 8,2 & 6,4 & 66,4 & 6,4 & 8,2 & 3,6 \\
\hline ЦП-5 & 0,5 & 0,5 & 19,6 & 11,0 & 40,2 & 7,2 & 17,2 & 3,8 \\
\hline
\end{tabular}

Прим.: ЦП - ценопопуляция; ј - ювенильное онтогенетическое состояние; im - имматурное; v - виргинильное; g1 - молодое генеративное; g2 - средневозрастное генеративное; g3 - старое генеративное; ss - субсенильное; s - сенильное.

Для выяснения особенностей полового полиморфизма и половой структуры ценопопуляций O. vulgare были исследованы биоморфологические показатели генеративных особей у обоеполых и женских форм растений (табл. 1). Сравнительный анализ признаков, таких, как число генеративных побегов и растущих корневищ в парциальном кусте, годичный прирост плагиотропных корневищ, условный возраст особи не выявил заметных различий между половыми формами растений во всех ценопопуляциях. Большинство исследованных признаков отличались значительной вариабельностью. Не обнаружено заметных различий между половыми формами по морфологическим признакам генеративных побегов, таких, как длина побега и соцветия, число паракладиев в соцветии; вариабельность признаков невысокая. Таким образом, в изученных ценопопуляциях $O$. vulgare не установлено значительных различий по вторичным половым признакам вида между женскими и обоеполыми особями. Исследование половой структуры вида показало, что во всех ценопопуляциях доля женских особей была ниже обоеполых и составляет от $18 \%$ до $31 \%$ от общего числа особей (табл. 3).

Таблица 3

\section{Соотношение обоеполых и женских особей в ценопопуляциях}

Origanum vulgare

\begin{tabular}{|c|c|c|}
\hline \multirow{2}{*}{ № ЦП } & \multicolumn{2}{|c|}{ Встречаемость особей, \% } \\
\cline { 2 - 3 } & обоеполые & женские \\
\hline ЦП-1 & 82 & 18 \\
\hline ЦП-2 & 76 & 24 \\
\hline ЦП-3 & 81 & 19 \\
\hline ЦП-4 & 74 & 26 \\
\hline ЦП-5 & 69 & 31 \\
\hline
\end{tabular}


Ранее при изучении половой структуры лесной ценопопуляции O. vulgare длиннокорневищной жизненной формы было установлено, что женские половые формы составляют около 18\% от общего числа особей [4]. Женские и обоеполые растения в лесном биотопе не обнаруживали разницы по биоморфологическим признакам генеративных побегов. Размножение особей происходило в основном вегетативно; семенные ювенильные и имматурные особи отмечались единично. В исследованных луговых популяциях растений вида наблюдались сходные явления: отсутствие фенотипических различий между половыми формами, вегетативное разрастание особей, небольшое участие в популяциях семенных особей. При исследовании половой дифференциации O. vulgare луговых сообществ европейской части России отмечалась более высокая доля женских половых форм (до 42$65 \%)$ [1; 2]. По данным этих авторов, генеративные побеги женских растений имели более высокую потенциальную семенную продуктивность по сравнению с обоеполыми растениями. Таким образом, сопоставляя литературные данные и результаты наших исследований, можно предположить, что доля женских растений будет выше в тех популяциях O. vulgare, в которых происходит увеличение роли семенного возобновления растений. В этом случае преимущество получают женские особи, которые отличаются более высокой репродуктивной способностью по сравнению с обоеполыми особями [1].

Установлено, что растения O. vulgare в луговых разнотравно-злаковых фитоценозах Республики Алтай и
Алтайского края формируют длиннокорневищную жизненную форму. Онтогенетические спектры всех исследованных популяций O. vulgare центрированные со значительным преобладанием средневозрастных генеративных особей, которые составляют 40,2-61,9\% от числа всех особей. Вклад семенного возобновления незначителен. Самоподдержание исследованных луговых ценопопуляций $O$. vulgare происходит в основном вегетативным путем. Во всех ценопопуляциях между женскими и обоеполыми особями не обнаружено заметных различий по фенотипическим признакам вида: числу генеративных побегов и растущих корневищ в парциальном кусте, годичному приросту плагиотропных корневищ, условному возрасту особи, длине побега и соцветия, числу паракладиев в соцветии. При исследовании половой структуры ценопопуляций установлено, что доля женских особей значительно ниже обоеполых и составляет от $18 \%$ до $31 \%$ от общего числа особей. Можно предположить, что вероятной причиной невысокой доли женских особей является отсутствие массового семенного возобновления растений в исследованных ценопопуляциях O. vulgare.

\section{ЛИТЕРАТУРА:}

1. Анисимова А.Г., Демьянова Е.И. Морфолого-анатомические особенности половых форм Origanum vulgare L. (Lamiaceae) // Растительные ресурсы. 2007. - Т. 43 (вып. 1). - С. 36-45.

2. Верещагина В.А., Маланина Л.И. О гинодиэции душицы обыкновенной // Научные доклады высшей школы (биол. науки). - 1974. - № 6. - С. 51-57.

3. Годин В.Н. Половой полиморфизм двудольных растений в Сибири // Сибир- 
ский экологический журнал. - 2014. T. 21 (№ 5). - С. 679-688.

4. Гордеева Н.И. Особенности полового полиморфизма растений Origanum vulgare L. (Lamiaceae) в окрестности Академгородка Новосибирской области // Раст. мир Азиатской России. - 2014. - № 3 (15). - С. 28-31.

5. Дарвин Ч. Различные формы цветов // Дарвин Ч. Соч.: в 8 т. [Т. 7]. - М.-Л.: АН СССР, 1948. - С. 31-251.

6. Демьянова Е.И. Половой полиморфизм цветковых растений: автореф. дис. ... докт. биол. наук. - М., 1990. - 35 с.

7. Дикорастущие полезные растения России / под ред. А.Л. Буданцева, Е.Е. Лесиовской. - СПб.: СПХФА, 2001. - 663 с.

8. Доронькин В.M. Род Origanum L. Душица // Флора Сибири: в 14-ти т. [T.11]. -Новосибирск: Наука, 1997. - С. 204-205.

9. Зайцев Г.Н. Математическая статистика в экспериментальной ботанике. - М.: Наука, 1984. - 424 с.

10. Заугольнова Л.Б. Ценопопуляции растений (очерки популяционной био- логии) / Л.Б. Заугольнова, Л.А. Жукова, А.С. Комаров и др. - М.: Наука, 1988. -188 c.

11. Нухимовский Е.Л., Черкасов О.А. Морфология Origanum vulgare L. в естественных местообитаниях и при выращивании в Московской области // Растительные ресурсы. - 1987. - Т. 23 (вып. 3). - С. 345-356.

12. Подгаевская Е.Н. Онтогенез душицы обыкновенной (Origanum vulgare L.) // Онтогенетический атлас лекарственных растений: учеб. пособие [Т. 3]. Йошкар-Ола: МарГУ, 2002. - С. 202-205.

13. Ценопопуляция растений (основные понятия и структура) / О.В. Смирнова, Л.Б. Заугольнова, И.М. Ермакова и др. М.: Наука, 1976. - 217 с.

14. Dufay M., Billard E. How much better are females? The occurrence of female advantage, its proximal causes and its variation within and among gynodioecious species // Annals of Botany. - 2012. - Vol. 109 (№. 3). - P. 505-519. 